\title{
Preserving CAD
}

\section{Data Types Series}

Artefactual Systems and the Digital Preservation Coalition

\section{DPC Technology Watch} Guidance Note July 2021 


\section{The Data Type Guidance Note Series}

Each Guidance Note in the Data Types series is designed to provide a primer on the current state of community knowledge about data types commonly encountered by those seeking to preserve digital holdings. Digital preservation is about keeping information findable, usable, and trustworthy over the long-term. The best approach for any repository will vary according to the scope and content of its holdings, available resources, and the expectations of its funders and users. There are however, broadly applicable good practices that have been established as a result of many years of research, practical implementation, and consensus building. These are presented here as a starting point, along with additional resources for further exploration.

This series of Data Type Guidance Notes has been authored by staff at Artefactual Systems in collaboration with the Digital Preservation Coalition. These notes have been developed in conjunction with the UK Nuclear Decommissioning Authority.

Digital preservation is an evolving field and continues to change and develop in response to external drivers and fresh challenges. New formats, standards, and examples of good practice will emerge over time and the information contained within this report will need to be updated. We welcome comments and feedback to: info@dpconline.org. 


\section{Overview of data type}

Computer-Aided Design (CAD) is a technology that was originally developed to assist engineers and architects to produce large and complex designs (Ball, 2013). CAD is used in fields such as architecture, landscape architecture, aerospace engineering, automotive design, civil and mechanical engineering, and archaeology. CAD is used to create precise technical specifications of products, designs, and the built environment. This purpose distinguishes CAD models in 2D (for example, a floor plan of a house) and 3D (for example, a solid model of an airplane part) from other forms of 3D modelling such as stereolithography and surface modelling used in fields such as animation, video games, film special effects, and point cloud capture. More information on the preservation of these types of 3D models, can be found in the Guidance Note on 3D (Artefactual \& DPC, 2021).

In recent years, Building Information Modelling (BIM) has supplemented or supplanted CAD as the tool of choice for designing and managing building projects. BIM produces a virtual representation of a building, including its architectural, structural, and other physical features in 2D and 3D, cost management, scheduled work time, energy data, and facility management information (Historic England [HE], 2017; Lindlar, 2020). Objects in a BIM model are parametric, meaning that changes made are automatically reflected in all views (e.g. 2D, 3D, and schedules) (HE, 2017).

\section{Preservation challenges}

The quantity and size of the data, the reliance on proprietary software, lack of compatibility between systems and links with other external systems and datasets all add to the challenges of preserving this complex data type.

\subsection{Software and file format obsolescence}

The CAD software market is highly competitive and volatile. It is not typically in the financial interest of CAD software vendors to support legacy format versions or full interoperability with competing formats (Ball, 2013; Whiteside, 2020). Many files created in CAD software from the 1960s to 2000s are now extremely difficult to render because the software either no longer exists or no longer opens early versions of the format (de Vletter, 2019). When appropriate software can be secured, knowledge about how to use it is often scant. Alternative software may be used with CAD models for activities such as generative design, creating photorealistic renders, and conducting walkthroughs of designs in virtual and augmented reality (Leventhal, 2018; Alizadehsalehi, 2020). Such software dependencies can introduce additional layers of obsolescence.

\subsection{System incompatibility}

CAD systems rely on complex mathematical modelling kernels (Wikipedia, 2021) to accurately represent curved surfaces (surface modelling) and solids with properties such as mass and volume (solid modelling). CAD files are essentially instructions for using a given kernel, and kernels vary between CAD software systems. Translating a model from one CAD software to a different one or even a newer version with a different modelling kernel can result in changes to model geometry. Loss of data is common during file format migrations, particularly for non-geometric data within CAD models (Ball, 2013). 


\subsection{References between files}

CAD models frequently import model pieces such as title blocks, layers, textures, and reusable components from externally linked files (called 'Xrefs' in AutoCAD and many other CAD systems) (Autodesk, 2018). Links to externally referenced files stored as absolute filepaths will break when files are moved from their original storage location. External references saved as relative filepaths will break if files are not retained in the aggregation, using the original directory structure. Broken Xrefs will typically cause an error message when loading the affected CAD model in appropriate software, and the model may not load or display correctly. Xrefs can be relinked but this may require substantial effort.

It is possible in most CAD software to 'bind' external references into a CAD model to make the file self-contained for easier preservation and transmission. This can be a laborious process but greatly simplifies the preservation of CAD models as discrete objects.

\subsection{Volume and volatility}

In large building projects, it is common for architects, engineers, and designers to use different CAD and 3D modelling software packages and file formats at various stages in the design and construction process (Leventhal, 2018). Such projects frequently result in a large number of digital files, including models in several formats and many versions of files that differ from each other slightly. It is not uncommon for building projects to result in thousands or hundreds of thousands of digital files (Smith, 2009; de Vletter, 2019).

\subsection{Institutional barriers to entry}

Successful preservation of CAD has been stalled in practice for many organizations by the reality and perception of barriers to entry for engaging with content (Leventhal, 2018; de Vletter, 2019; Whiteside, 2020).

- MIT's FACADE project attempted to address skills gaps with multi-disciplinary teams consisting of digital preservationists, architectural curators, CAD software specialists, and IT staff (Smith, 2009).

- The Canadian Centre for Architecture similarly found in its Archaeology of the Digital project that the combined input of architectural curators and researchers, digital archivists, and interviews conducted with record creators provided the necessary "architectural, technological, and historical context" to move forward with preserving and providing access to CAD models (de Vletter, 2019).

- The high cost of software licenses for CAD products is another barrier. Above-average hardware requirements for local copies of CAD software may also be prohibitive.

\section{File formats}

There is no single perfect format for the preservation and future use of CAD. Decisions made on file formats should be dependent on the features and functionality to be preserved and the future use cases to be supported. Note that the tables below do not provide an exhaustive list of formats and those that may be suitable for preservation and access. The most suitable format for preserving the important features and functionality of a file may be the original format that it was created in. It is recommended that careful research and analysis is carried out before migrating files to a new format. 


\begin{tabular}{|c|c|c|}
\hline File format & Extensions & Brief summary \\
\hline $\begin{array}{l}\text { Industry } \\
\text { Foundation } \\
\text { Classes } \\
\text { (IFC) }\end{array}$ & ifc & $\begin{array}{l}\text { IFC is a platform-neutral, open ISO 16739-1:2018 standard file format } \\
\text { specification for the exchange of BIM data (LC, 2016c; ISO, 2018). IFC } \\
\text { files are plain-text files, which may optionally be encoded in XML } \\
\text { and/or compressed. The commonly used clear text variant, IFC-SPF, is a } \\
\text { fully conformant STEP Physical File (see Standard for the Exchange of } \\
\text { Product, below). IFC has wide support in modern BIM systems such as } \\
\text { Revit and ArchiCAD. BuildingSMART's (2021) certified software list } \\
\text { shows those that have or those that are working towards compliance } \\
\text { with IFC. } \\
\text { Use and delivery of IFC is legally required for publicly-funded building } \\
\text { projects in several countries (Sacks et al., 2018). IFC is recognized as a } \\
\text { preservation target format (DURAARK, 2015; Smith, 2009) and an } \\
\text { acceptable format (LC, 2020-2021) for BIM by several organisations. } \\
\text { ifcOpenShell is an open-source tool for working with IFC files. Several } \\
\text { free readers are available for the format (LC, 2016c). }\end{array}$ \\
\hline $\begin{array}{l}\text { Standard } \\
\text { for the } \\
\text { Exchange } \\
\text { of Product } \\
\text { Model } \\
\text { Data (STEP) }\end{array}$ & $\begin{array}{l}. \text { stp, } \\
. \text { step, } \\
. p 21\end{array}$ & 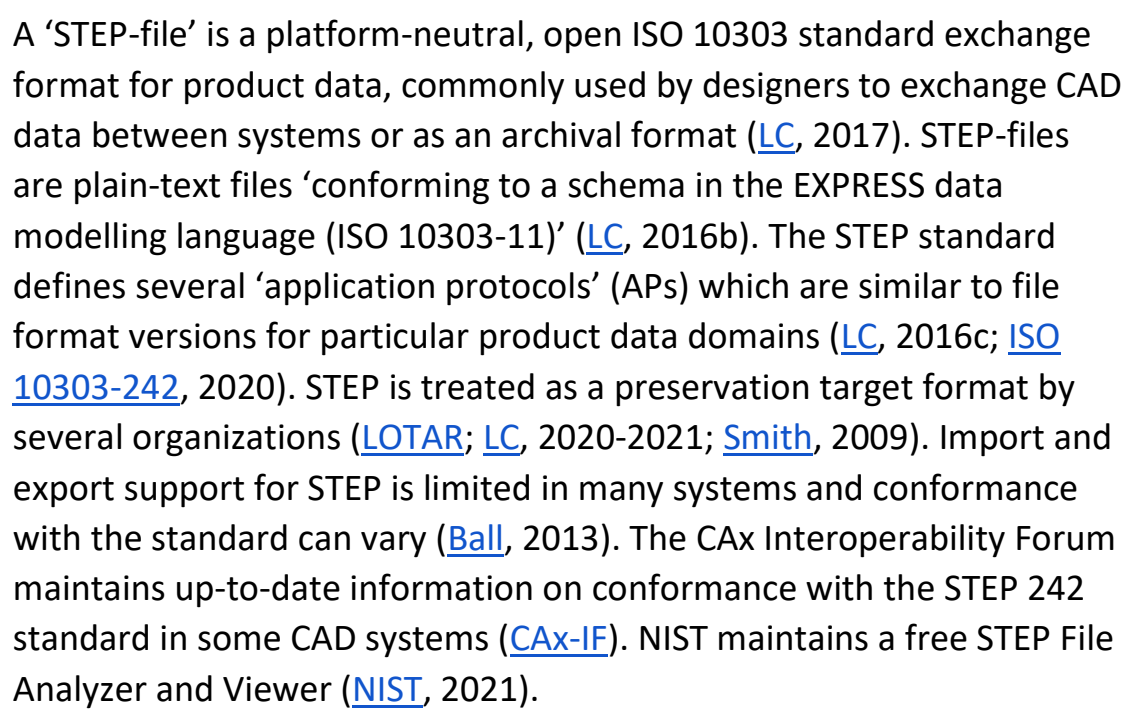 \\
\hline $\begin{array}{l}\text { AutoCAD } \\
\text { Drawing } \\
\text { (DWG) }\end{array}$ &.$d w g$ & $\begin{array}{l}\text { DWG is the proprietary binary native format for Autodesk's AutoCAD, } \\
\text { one of the most widely used 2D and 3D CAD programs (Library of } \\
\text { Congress (LC), 2020a). A partial, unofficial specification of the file } \\
\text { format is available from the Open Design Alliance (2018). Several } \\
\text { Software Development Kits (SDKs) and a number of CAD systems } \\
\text { support reading and writing DWG files. As of 2020, current versions of } \\
\text { AutoCAD can read current and preceding file versions (Suchocki, 2020). } \\
\text { Several organizations consider DWG to be an acceptable or } \\
\text { recommended format for collecting and storing 2D and 3D CAD files }\end{array}$ \\
\hline
\end{tabular}




\begin{tabular}{|c|c|c|}
\hline & & $\begin{array}{l}\text { (LC, 2020-2021; UK Data Service, 2020; Archaeology Data Service } \\
\text { (ADS), 2020). }\end{array}$ \\
\hline $\begin{array}{l}\text { ARCHICAD } \\
\text { Archive File } \\
\text { (PLA) }\end{array}$ & .pla & $\begin{array}{l}\text { PLA is a proprietary binary file format for Graphisoft ARCHICAD that } \\
\text { bundles library parts, linked images and textures associated with the } \\
\text { project into a single self-contained file (Graphisoft, 2021b). PLA is not } \\
\text { widely supported outside of ARCHICAD. }\end{array}$ \\
\hline $\begin{array}{l}\text { ARCHICAD } \\
\text { Project File } \\
\text { (PLN) }\end{array}$ & .pln & $\begin{array}{l}\text { PLN is the proprietary binary file format for Graphisoft ARCHICAD, an } \\
\text { architecturally focused BIM and 2D/3D CAD software. Objects in } \\
\text { ARCHICAD are parametric and semantically rich components of a } \\
\text { 'virtual building' (Graphisoft, 2021a). }\end{array}$ \\
\hline $\begin{array}{l}\text { Microstatio } \\
\text { n Drawing } \\
\text { (DGN) }\end{array}$ & .dgn & $\begin{array}{l}\text { DGN is the proprietary binary native format for Bentley Systems' } \\
\text { Microstation, a widely used 2D and 3D CAD program especially popular } \\
\text { in architecture and civil engineering projects such as highways and } \\
\text { bridges. DGN files can also be opened in Autodesk's AutoCAD as well as } \\
\text { in free readers such as Bentley View. }\end{array}$ \\
\hline $\begin{array}{l}\text { Revit } \\
\text { Project File } \\
\text { (RVT) }\end{array}$ & .rvt & $\begin{array}{l}\text { RVT is the proprietary binary file format for Autodesk's Revit BIM } \\
\text { software. RVT files contain the full range of information in a BIM, } \\
\text { including 3D models, 2D representations such as plans and elevations, } \\
\text { cost information, and time schedules. Objects in a RVT file are } \\
\text { frequently pulled in from linked 'family files', which are libraries of } \\
\text { semantically rich objects pulled from external data sources or } \\
\text { developed locally to support component re-use. Revit automatically } \\
\text { updates older versions of the RVT file format on opening (Suchocki, } \\
\text { 2020). }\end{array}$ \\
\hline $\begin{array}{l}\text { SketchUp } \\
\text { Model } \\
\text { (SKP) }\end{array}$ &.$s k p$ & $\begin{array}{l}\text { SKP is the proprietary binary file format for Trimble SketchUp, formerly } \\
\text { known as Google SketchUp, a 3D modelling software application with } \\
\text { CAD capabilities. The SketchUp software and file format: exploration of } \\
\text { the options for digital preservation report (Vanstappen, 2019) has } \\
\text { more information on the SketchUp format and digital preservation. } \\
\text { This report also resulted in multiple versions of SketchUp being added } \\
\text { to the PRONOM format registry for format identification. }\end{array}$ \\
\hline $\begin{array}{l}\text { Initial } \\
\text { Graphics } \\
\text { Exchange } \\
\text { Specificatio } \\
\mathrm{n} \text { (IGES) }\end{array}$ & $\begin{array}{l}\text {.igs, } \\
\text {.iges }\end{array}$ & $\begin{array}{l}\text { IGES is a platform-neutral, open-standard lightweight file format } \\
\text { specification for the exchange of CAD model geometry (Eclipse } \\
\text { Foundation, 2016). IGES files are ASCII-based plain-text files. IGES has } \\
\text { historically been and continues to be supported as an import and } \\
\text { export format in a large number of CAD systems. Implementations of } \\
\text { the standard vary between CAD systems, and there is no mechanism }\end{array}$ \\
\hline
\end{tabular}




\begin{tabular}{|c|c|c|}
\hline & & $\begin{array}{l}\text { for testing standard conformance. This limits the effectiveness of IGES } \\
\text { as an interoperable exchange format (Ball, 2013; Wilson, 1987). } \\
\text { The MIT FACADE project considers IGES to be a target format for } \\
\text { simplified derivatives of CAD models (Smith, 2009). }\end{array}$ \\
\hline $\begin{array}{l}\text { Engineerin } \\
\text { g Format } \\
\text { Document } \\
\text { (PDF/E-1) }\end{array}$ &.$p d f$ & $\begin{array}{l}\text { 'PDF/E-1 is a constrained form of Adobe PDF intended to be suitable } \\
\text { for exchange of } 2 D \text { and } 3 D \text { documentation in building and } \\
\text { manufacturing workflows.' (LC, } 2019) \text {. PDF/E-1 is intended for } \\
\text { exchange of engineering documentation during building and } \\
\text { manufacturing processes. Its portability and support for features of } \\
\text { CAD data such as layers make it a candidate as an access format in } \\
\text { many use cases. } \\
\text { Development of PDF/E-2 stalled in part due to overlapping } \\
\text { functionality with PDF } 2.0 \text { (ISO } 32000-1)(\underline{L C}, 2019) \text {. This may call into } \\
\text { question its future viability. }\end{array}$ \\
\hline
\end{tabular}

\section{Metadata standards}

- Buildm is a descriptive metadata standard for Architectural Data Objects (DURAARK, 2015). Its data model draws a distinction between the Physical Asset and the Digital Object to disambiguate the many optional fields. The Physical Asset requires latitude and longitude fields, while the Digital Object requires information about the object creator and filename.

- If $\mathrm{cm}$ is a technical metadata standard for IFC file formats (Lindlar, 2020).

- COBie or Construction-Operations Building Information Exchange is a metadata standard intended to support facilities management and handover of buildings. It is included in the United States National BIM Standard (NBIMS-US V3) (WBDG, 2021).

\section{Tips for creators}

Few resources exist to provide guidance to CAD and BIM creators on long-term preservation of their files. However, the following tips provide a useful starting point:

For architects and engineers:

- Manage externally referenced files. Prefer relative paths over absolute; bind external references prior to transferring files to an archival repository when possible.

- Use consistent naming conventions. Consistent and documented naming conventions for files, project folders, layers, and other work outputs greatly ease the process of appraising, describing, and conducting research on project records. 
- Document the context of design files. Documentation should cover details of project team members and responsibilities; workflows; software used; and client, legal, and other requirements. Project summary narratives can add valuable contextual information to the files.

- Export high-value CAD models and BIMs to high-fidelity open formats. In addition to retaining original formats, save selected CAD models and BIMs in open formats such as STEP and IFC. This is best done soon after creation and by skilled operators of the software. Creating STEP or IFC derivatives before transferring files to an archive may greatly increase the longevity of the models though checks should always be made to ensure these new versions retain the important features of the models.

For clients such as building owners and facilities managers:

- Require open standards. Require that project architects and engineers turn in deliverables in open formats such as STEP and IFC, ideally in addition to the design files in their native file format. For example, IFC is the standard for public projects for some European Union nations (Leventhal, 2018).

- Ask for as-builts. Changes to building designs are common on building sites. As-built drawings or models created during or after construction reflect the built reality rather than initial design of a building, but are not always created. One way to guarantee delivery of asbuilts is to make final payment conditional on their delivery.

\section{Tips for archivists}

\subsection{General guidance}

The following resources provide guidance on preserving and providing access to CAD and related files:

- Preserving Computer-Aided Design (CAD) Technology Watch Report (Ball, 2013).

- Preserving 3D Design and Construction Records Technology Watch Report (Leventhal \& Thompson, forthcoming).

\subsection{Acquisition and appraisal}

- Gather as much contextual project information as possible during appraisal and acquisition. Written documentation, oral histories, and informal interviews with project staff can provide considerable insight into the structure and purpose of project files and provide useful information for preservation (Haagsma, 2018; de Vletter, 2018).

- Acquire and maintain appropriate rendering software. Successful access and re-use of CAD models and BIMs is dependent on having access to the right software. Free and/or opensource viewer software may suffice for some use cases, while full versions of CAD or BIM software may be required for others. Software preservation and emulation may be an appropriate solution for appraisal and long-term access to highly software-dependent CAD models (Work, 2019). 


\subsection{Characterization}

Characterization can be useful to identify file formats, extract metadata, identify broken or encrypted content, or check conformance to profiles or standards. Tool support and effectiveness can vary considerably for different file formats.

- Identify file formats with a tool such as DROID, FIDO, or Siegfried that uses the PRONOM file format registry.

- Validating that a model's geometry and other significant properties were correctly retained during a file format migration is difficult and time consuming (Ball, 2013). The LOTAR standard (Long Term Archiving and Retrieval) places heavy emphasis on validating migrations with a specified set of "validation properties", but the criteria have not been generally adopted outside the aerospace and defence sector (Leventhal, 2018).

\subsection{Preservation action}

- Be mindful with file format migrations. Data loss is common in CAD and BIM file format migrations, and can be difficult to discern (ADS, 2011). When migrating or normalizing these models, be sure to retain the original files. Be careful to ensure that the chosen preservation format and migration pathway will retain the significant properties of the original models. For example, parametric data is commonly lost in migrations but may not be significant for all use cases. When possible, it may be wise to create multiple derivatives of selected models in a range of formats, as practiced in the MIT FACADE project (Smith, 2009).

\subsection{Technical considerations}

- Do not let perfect be the enemy of the good. Not all users and use cases require retaining the full fidelity and ability to reuse CAD model data. Floor plans or less granular 3D models that depict a project's geometry in lightweight exchange and access formats may suffice for many designated communities. Derivatives in other formats, such as video flythroughs of 3D CAD models, can also be very useful for exhibition and communication with lay audiences.

- Pay attention to layers. In CAD models, layers are used to separate data by function or purpose, and to selectively turn on or off their display. Use of layers in architectural workflows is relatively standardized. In archaeology, layers are used in more diverse ways (Ball, 2013). CAD models are often saved with many layers turned off. Ensure that all layers are visible before determining that a CAD model is devoid of content.

\section{References}

Alizadehsalehi, S., Hadavi, A., \& Huang, J. C. (2020) From BIM to Extended Reality in AEC Industry. Automation in Construction 116. DOI: 10.1016/i.autcon.2020.103254

Archaeology Data Service [ADS] (2020. Guidelines for depositors. Available at: https://web.archive.org/web/20201128143324/https://archaeologydataservice.ac.uk/advice/Downl oads.xhtml

Archaeology Data Service (2011) CAD: A Guide to Good Practice, Section 3.2: CAD Data Formatshttps://web.archive.org/web/20201130144210/https://guides.archaeologydataservice.ac.u k/g2gp/Cad 3-2

Artefactual \& DPC (2021a) Preserving 3D. Available at: http://doi.org/10.7207/twgn21-14 
Autodesk (2018) About Attaching and Detaching Referenced Drawings (Xrefs). Available at: https://web.archive.org/web/20201112022941/https://knowledge.autodesk.com/support/autocad/ getting-started/caas/CloudHelp/cloudhelp/2018/ENU/AutoCAD-Core/files/GUID-A987D2FF-45BD474E-99C1-E6316A42F667-htm.html

Autodesk (2017) About the DXF Format (DXF). Available at: https://web.archive.org/web/20200917202132/http://help.autodesk.com/view/ACD/2017/ENU/?g uid=GUID-235B22E0-A567-4CF6-92D3-38A2306D73F3

Ball, A. (2013) Preserving Computer-Aided Design (CAD). DPC Technology Watch Report 13-02. Available at: http://dx.doi.org/10.7207/twr13-02

buidingSMART (2021) Certified software. Available at:

https://web.archive.org/web/20210305071013/https://www.buildingsmart.org/compliance/softwar e-certification/certified-software/

CAx Interoperability Forum (n.d) AP242 Implementation Coverage. Available at:

https://web.archive.org/web/20210204130420/https://www.cax-if.org/cax/vendor info.php

de Vletter, M. (2019) Don't Be Afraid of the Digital. Arts 8(1), 6;

https://doi.org/10.3390/arts8010006

Durable Architectural Knowledge [DURAARK]. Lindlar, M., Panitz, M, \& Gadiraju, U. (2015) Ingest and Storage of 3D Objects in a Digital Preservation System. DOI: 10.5281/zenodo.1115512. Available at: https://zenodo.org/record/1115512

Eclipse Foundation (2016) IGES file specification. Available at:

https://web.archive.org/web/20201022043439/https://wiki.eclipse.org/IGES file Specification

ASD-STAN (2018) EN 9300, Aerospace series - LOTAR - Long Term Archiving and Retrieval of DigitalTechnical Product Documentation such as 3D,CAD and PDM Data, multipart standard. Brussels: European Committee for Standardization Available at:

https://web.archive.org/web/20201202025415/https://asd-stan.org/downloads/lotar-9300-seriesset-16-current-standards-mix-of-prens-and-din-ens/

Graphisoft (2021a) Archicad Archive Files: let's talk about the PLA. Available at: https://web.archive.org/web/20210204130719/https://graphisoft.com/us/archicad-archive-fileslets-talk-about-the-pla

Graphisoft (2021b) Elements of the Virtual Building. ARCHICAD 22 Reference Guide. Available at: https://web.archive.org/web/20200930102336/https://helpcenter.graphisoft.com/userguide/76425/

Haagsma, L. (2018) Meeting of Experts: Archiving Digital Architectural Heritage. Het Nieuwe Instituut. Available at:

https://web.archive.org/web/20201129072927/https://collectie.hetnieuweinstituut.nl/en/preservat ion/meeting-experts-archiving-digital-architectural-heritage

Historic England [HE] (2017) BIM for Heritage: Developing a Historic Building Information Model. https://web.archive.org/web/20210122130817/https://historicengland.org.uk/imagesbooks/publications/bim-for-heritage/

IfcOpenShell (2020) IfcOpenShell: the open source ifc toolkit and geometry engine. Available at: https://web.archive.org/web/20201117015434/http://ifcopenshell.org/ 
ISO. (2020). ISO 10303-242:2020: Industrial automation systems and integration - Product data representation and exchange - Part 242: Application protocol: Managed model-based 3D engineering. Available at:

https://web.archive.org/web/20200917211639/https://www.iso.org/standard/66654.html

ISO. (2018). ISO 16739-1:2018: Industry Foundation Classes (IFC) for data sharing in the construction and facility management industries. Available at:

https://web.archive.org/web/20210130074642/https://www.iso.org/standard/70303.html

ISO (2016) ISO 10303-21:2016: STEP-file, ISO 10303-21 -- Industrial automation systems and integration -- Product data representation and exchange -- Part 21: Implementation methods: Clear text encoding of the exchange structure. Available at:

https://web.archive.org/web/20201021082755/https://www.iso.org/standard/63141.html

Leventhal, A. (2018) A report on the Architecture, Design and Engineering Summit organized by the Library of Congress, the National Gallery of Art and the Architect of the Capitol on November 16 \& 17, 2017 at the Library of Congress. Available at:

https://web.archive.org/web/20201105045954/https://www.loc.gov/preservation/digital/meetings /DesigningTheFutureLandscapeReport.pdf

Leventhal, A and Thompson, J (forthcoming) Preserving 3D Design and Construction Records. DPC Technology Watch Report

Library of Congress [LC] (2020-2021) Recommended Formats Statement: VIII. Design and 3D, i. 2D and 3D Computer Aided Design. Available at:

https://web.archive.org/web/20201016221933/https://www.loc.gov/preservation/resources/rfs/de sign3D.html

Library of Congress (2020a) DWG (AutoCAD Drawing) Format Family. Available at:

https://web.archive.org/web/20201101015426/https://www.loc.gov/preservation/digital/formats/f dd/fdd000445.shtml

Library of Congress (2020b) Scalable Vector Graphics (SVG) File Format Family. Available at:

https://web.archive.org/web/20201129085108/https://www.loc.gov/preservation/digital/formats/f dd/fdd000515.shtml

Library of Congress (2019) PDF/E-1, Engineering Document Format, ISO 24517-1:2008. Available at: https://web.archive.org/web/20201030114623/https://www.loc.gov/preservation/digital/formats/f dd/fdd000495.shtml

Library of Congress (2017) STEP-file, ISO 10303-21. Available at:

https://web.archive.org/web/20201018111206/https://www.loc.gov/preservation/digital/formats/f dd/fdd000448.shtml

Library of Congress (2016a) DXF (AutoCAD Drawing Interchange Format) Family, ASCII variant.

Available at:

https://web.archive.org/web/20201103140604/https://www.loc.gov/preservation/digital/formats/f dd/fdd000446.shtml 
Library of Congress (2016b) EXPRESS data modeling language, ISO 10303-11. Available at:

https://web.archive.org/web/20201024095520/https://www.loc.gov/preservation/digital/formats/f dd/fdd000449.shtml

Library of Congress (2016c) Industry Foundation Classes (IFC), Clear Text Family. Available at: https://web.archive.org/web/20201024182048/https://www.loc.gov/preservation/digital/formats/f dd/fdd000447.shtml

Lindlar, M. (2020) A practical case study about metadata, Leibniz Information Centre for Science and Technology. Available at:

https://web.archive.org/web/20201028210115/https://www.dpconline.org/events/pastevents/preserving-3d-digital-engineering-models-a-briefing-day

Nagel, R., N., Braithwaite, W. W., \& Kennicott, P. R. (1980) Initial Graphics Exchange Specification IGES Version 1.0. NBSIR 80-1978. National Bureau of Standards. Available at:

https://web.archive.org/web/20201208073815/https://nvlpubs.nist.gov/nistpubs/Legacy/IR/nbsir80 -1978.pdf

National Institute of Standards and Technology [NIST] (2021) STEP File Analyzer and Viewer.

Available at: https://web.archive.org/web/20201213150431/https://www.nist.gov/servicesresources/software/step-file-analyzer-and-viewer

O'Connell, C. (1988) CAD/CAM (Computer-Aided Manufacturing): A History of the Technology and Guide to the Literature Part II. Science \& Technology Libraries 8(1), p. 129. DOI:

10.1300/J122v08n01_10

Open Design Alliance . (2018). Open Design Specification for .dwg files, Version 5.4.1. Available at: https://web.archive.org/web/20201111032256/https://www.opendesign.com/files/guestdownload s/OpenDesign Specification for .dwg files.pdf

Sacks, R., Chuck Eastman, C., Ghang Lee, G., \& Teicholz., P. (2018). BIM Handbook: A Guide to Building Information Modeling for Owners, Designers, Engineers, Contractors, and Facility Managers (3rd ed). Hoboken: John Wiley \& Sons, 326-327.

Smith, M. (2009) Final Report for the MIT FACADE Project: October 2006 -August 2009. Available at: https://web.archive.org/web/20200917202101/https://www.vai.be/volumes/general/FACADEFinalR eport.pdf

Suchocki, M, (Autodesk UK) (2020) Future proofing 3D models: a software industry perspective.

Available at:

https://web.archive.org/web/20201028210115/https://www.dpconline.org/events/past-

events/preserving-3d-digital-engineering-models-a-briefing-day

The National Archives (2020) The Technical Registry: PRONOM. Available at:

https://web.archive.org/web/20201111032324/http://www.nationalarchives.gov.uk/PRONOM/Defa $\underline{\text { ult.aspx }}$

UK Data Service (2020) Recommended file formats. Available at:

https://web.archive.org/web/20200917202123/https://www.ukdataservice.ac.uk/managedata/format/recommended-formats.aspx

Vanstappen, H. (2019) SketchUp software and file format: Exploration of the options for digital preservation. Available at: https://doi.org/10.5281/zenodo.3718995 DOI: 10.5281/zenodo.3718995 
Whiteside, A. (2020) Archiving the Built Environment: the collective challenge. Available at: https://web.archive.org/web/20201008185720/https://www.dpconline.org/events/pastevents/preserving-3d-digital-engineering-models-a-briefing-day

Whole Building Design Guide [WBDG] (2021) Construction-Operations Building Information Exchange (COBie). Available at:

https://web.archive.org/web/20201128092905/https://www.wbdg.org/resources/constructionoperations-building-information-exchange-cobie

Wikipedia (2021) Geometric modeling kernel. Available at:

https://web.archive.org/web/20201112013436/https://en.wikipedia.org/wiki/Geometric modeling kernel

Wilson, P.R. (1987). A View of PDES. Internal Report. Gaithersburg, MD: National Bureau of Standards.

Work, L. (2019, September 1) FCoP 2020 Cohort Reflections: University of Virginia. Software Preservation Network. Available at:

https://web.archive.org/web/20210126184535/https://www.softwarepreservationnetwork.org/fco p-2019-cohort-reflections-university-of-virginia/ 